\title{
The geographic distribution of mammography resources in Mississippi
}

\author{
Elizabeth N. Nichols ${ }^{1}$, Denae L. Bradley ${ }^{1}$, Xu Zhang $^{2}$, Fazlay Faruque ${ }^{3}$ and Roy J. Duhé ${ }^{4}$ \\ 1. Murrah High School, Jackson, MS 39216, USA. \\ 2. Center of Biostatistics \& Bioinformatics, University of Mississippi Medical Center, Jackson, MS 39216- \\ 4505, USA. \\ 3. GIS \& Remote Sensing Program, University of Mississippi Medical Center, Jackson, MS 39216-4505, \\ USA. \\ 4. Department of Pharmacology and Toxicology \& Department of Radiation Oncology, University of \\ Mississippi Medical Center, Jackson, MS 39216-4505, USA.
}

\begin{abstract}
OBJECTIVE: To determine whether the availability of mammography resources affected breast cancer incidence rates, stage of disease at initial diagnosis, mortality rates and/or mortality-to-incidence ratios throughout Mississippi. METHODS: Mammography facilities were geocoded and the numbers of residents residing within a thirty minute drive of a mammography facility were calculated. Other data were extracted from the Mississippi Cancer Registry, the U.S. Census, and the Mississippi Behavioral Risk Factor Surveillance Survey (BRFSS). RESULTS \& DISCUSSION: There were no statistically-significant differences between breast cancer incidence rates in Black versus White females in Mississippi; however, there were significant differences in the use of mammography, percentages of advancedstage initial diagnoses, mortality rates, and mortality-to-incidence ratios, where Black females fared worse in each category. No statistically-significant correlations were observed between breast cancer outcomes and the availability of mammography facilities. The use of mammography was negatively correlated with advanced stage of disease at initial diagnosis. By combining Black and White subsets, a correlation between mammography use and improved survival was detected; this was not apparent in either subset alone. There was also a correlation between breast cancer mortality-to-incidence ratios and the percentage of the population living below the poverty level. CONCLUSIONS: The accessibility and use of mammography resources has a greater impact on breast cancer in Mississippi than does the geographic resource distribution per se. Therefore, intensified mammography campaigns to reduce the percentage of advanced-stage breast cancers initially diagnosed in Black women, especially in communities with high levels of poverty, are warranted in Mississippi.

KEY WORDS: Breast Cancer; Mammography; Health Disparities; Geographic Information System (GIS)

Correspondence: rduhe@umc.edu

DOI: $10.5210 /$ ojphi.v5i3.4982

Copyright @2014 the author(s)

This is an Open Access article. Authors own copyright of their articles appearing in the Online Journal of Public Health Informatics. Readers may copy articles without permission of the copyright owner(s), as long as the author and OJPHI are acknowledged in the copy and the copy is used for educational, not-for-profit purposes.
\end{abstract}




\section{Introduction}

Breast cancer is the most frequently-occurring cancer in women; fortunately, breast cancer mortality rates have steadily declined in the United States since 1990 [1,2]. This decline appears to have resulted from the combined benefits of the increased use of screening mammography and adjuvant therapy. However, improvements in breast cancer survival have not been uniform in all populations and in all geographic regions throughout the nation. Most notably, despite their lower incidence rates for breast cancers, Black women die from these diseases at higher rates than do White women, and this trend has persisted for many years [3]. Given that approximately $37 \%$ of Mississippians are of African ancestry, the disparate outcomes affecting AfricanAmerican women may have a significant impact on Mississippi's cancer burden. An important aim of this study is to compare cancer outcomes between Black and White female Mississippi residents and to explore the possible reasons for the differential outcomes. However, there are other demographic characteristics of particular relevance to Mississippi, and these too may result in a worsened overall impact due to breast cancer mortality rates. Relative to the other states in America, Mississippi has one of the lowest levels of educational attainment [4] and lowest rates of high school graduation [5]. Mississippi has chronically ranked as one of the poorest states in the USA, whether measured by childhood poverty rates [6], median household income ${ }^{1}$ or by percentage of the population living below poverty level [7]. It has been well-documented that low socio-economic status (SES) parameters such as literacy and income [8,9] are generally associated with higher cancer mortality rates, and this is also true for breast cancer mortality rates [10]. To better understand how SES parameters can affect breast cancer mortality rates, much research has been invested in understanding the relationships between SES and specific aspects of health care consumption and delivery. This is a complicated issue, and these relationships may not be preserved in all geographic locations, because health care systems are subject to regional variations. In fact, some studies suggest that, although early-stage cancers are less likely to be detected in poor areas due to decreased mammography rates, this has no overall bearing on breast cancer survivorship [11].

Some aspects of racial disparity are difficult to understand. For example, Maly and co-workers described a pronounced disparity in the diagnostic delay between Black women and White women with breast cancer, regardless of whether their breast abnormalities were initially selfdetected or detected by health care providers [12]. A study conducted with a South Carolina cohort also found racial disparities in the interval time between the first abnormal clinical breast examination and determination of final status in economically-disadvantaged Black versus White women, although there was no significant disparity associated with overall completion of mammographic work-up [13]. It is unclear why such delays should be greater for Black women with breast cancer than for comparable White women.

In addition to the socio-economic factors that might contribute to racial disparities in breast cancer outcomes, one must also consider the influence of biological factors contributing to these disparities. There are a variety of breast cancer subtypes which can be distinguished by their gene expression profiles, and these subtypes correlate with differing clinical outcomes [14,15]. For example, patients with the luminal A breast cancer subtype have very good survival prospects, and approximately $90 \%$ of such patients can expect to be long-term survivors. In contrast, patients with the basal-like breast cancer subtype have the least favorable survival odds, and may not survive longer than four years post-diagnosis. The immunohistochemical tools 
routinely used by clinical pathology laboratories to verify the presence of estrogen receptor $\alpha$, progestin receptor B and HER2/Neu (human epidermal growth factor receptor 2) have been useful in identifying major breast cancer subtypes in patients. The luminal A and B subtypes both express estrogen receptor $\alpha$, for example, which indicates that these tumors may respond to endocrine therapy with aromatase inhibitors or selective estrogen receptor modulators (SERMs). HER2 amplification and overexpression is a significant diagnostic feature which indicates that a tumor may respond to trastuzumab, lapatinib or pertuzumab therapy. The basal-like breast cancer subtype, in contrast, often presents with an immunohistochemically "triple-negative" phenotype, i.e., these breast cancers lack immunoreactivity for estrogen receptor $\alpha$, progestin receptor B and do not contain genomic amplification of HER2/Neu. Basal-like tumors can be treated with chemotherapy, but a substantial fraction of these tumors respond poorly to therapy and have a poor prognosis.

Over a decade has passed since five breast cancer subtypes (Luminal A, Luminal B, Normal-like, Basal-like and Her2-enriched) were first identified by distinctive gene expression profiles, and during that interval much has been learned about how these subtypes may contribute to the population-based disparities in breast cancer mortality. It is now well-established that not all populations possess an equal distribution of these subtypes. Recently, genome-wide association studies identified a common risk variant for ER-negative breast cancer on chromosome 5p15, and the allele frequency of this variant was nearly twice as high in women of African ancestry as it was for women of European ancestry [16]. "Triple-negative" breast cancers [TNBC] themselves are a highly heterogeneous group that may include up to 6 different subtypes (Basallike 1, Basal-like 2, Mesenchymal, Mesenchymal Stem-like, Immunomodulatory and Androgenreceptor enriched) that respond differently to treatment [17,18]. It is still unknown whether these subtypes are differently distributed among different ethnic groups. TNBCs are disproportionately observed in women of African ancestry. This observation has been corroborated in numerous U.S. studies, including those based on the California Cancer Registry [19,20], the Carolina Breast Cancer Study [21,22], a Thomas Jefferson University Hospital cohort [23] and the SEER database [23]. The high prevalence of these aggressive cancers in women of African ancestry is a worldwide phenomenon and is clearly rooted in biological diversity. In one study the prevalence of "triple-negative" breast cancers in Ghanian women was reported to be as high as $82 \%$ versus a $16 \%$ prevalence in American women of European ancestry [24]. While the prevalence of triplenegative/basal-like breast cancer is clearly higher in women of African versus European ancestry, it appears that the prognosis for survival may be equally grim for women of all races and ethnicities afflicted by this aggressive cancer subtype, but only when patient cohorts are properly matched for other factors that affect survival $[25,26]$.

In addition to research that focuses on TNBC breast cancer subtypes, other research has investigated other possible biological explanations of population-based breast cancer mortality disparities. One group has observed more extensive $\mathrm{CpG}$ island methylation in the promoters of the RASSF1A, RAR $\beta 2$ and $C D H 13$ loci in tumors taken from women of African versus European ancestry [27]. Methylational silencing of tumor suppressor genes commonly occurs through such mechanisms. Since these authors also observed an association between worse overall survival and higher methylation in these loci, they suggested that their discovery would be consistent with a biological explanation of disparity [27]. 
As stated earlier, a major factor in the national decline in breast cancer mortality has been the increasing use of screening mammography. Based on this evidence [28], the U.S. Preventive Services Task Force (USPSTF) recommended mammography screening every 1 to 2 years for women age 40 years and older in 2002 [29]. In 2009, however, the USPSTF recommended against routine mammography screening for women age $40-49$, and they also recommended against clinicians teaching women how to perform breast self-exams [30]. These changes in USPSTF recommendations were not without controversy, and several responses and rebuttals to the 2009 USPSTF recommendations have been noted. Despite the new USPSTF recommendations, the majority of primary care physicians favor aggressive mammography screening of women from ages 40 to 79 [31]. The American Cancer Society continues to advise average-risk women to begin mammography screening at age 40, and they also recommend clinical breast exams every three years for women between the ages of 20 to 39 [32].

However, mammography is a capital-intensive diagnostic procedure, and in a poor (relative to U.S. standards) rural state such as Mississippi, it may be difficult for all women to have easy access to mammography facilities. One should bear in mind that there are two aspects to be considered: availability and accessibility. Resource availability refers to the physical presence of that resource; because all mammography facilities must be certified by the U.S. F.D.A, one can literally map mammography availability throughout the state. Resource accessibility refers to the ability of a given individual to use that resource; this can be a much more complex aspect to quantify because it encompasses socioeconomic barriers to use, such as transportation to the resource, ability to pay for resource use, etc.

In this manuscript we examine publicly-accessible data concerning breast cancer in Mississippi to determine whether the geographic distribution of mammography facilities has a discernible effect on breast cancer outcomes in the state. The hypothesis to be tested is that limited availability of mammography facilities limits the accessibility of these resources, which results in an increased advanced stage at initial diagnosis and increased breast cancer mortality.

\section{Methods}

\section{Spatial Analysis}

Spatial analysis in this project involved delineating areas within 30-minute drive time distance from the mammography facilities and then identifying demographic characteristics within and outside the drive time areas by apportioning data from Census Block Groups. A spreadsheet for mammography facilities with data from the U.S. Food and Drug Administration's Mammography Facility Database (http://www.accessdata.fda.gov/scripts/cdrh/cfdocs/cfmqsa/mqsa.cfm) was prepared to geocode using ArcGIS 10.1 (Environmental Systems Research Institute, Inc., Redlands, California). A map was created showing the location of the geocoded facilities along with the counties and major transportation network in Mississippi (Figure 1). Using the same GIS software areas within and outside the drive time distance in respect to all mammography facilities were identified based on optimum driving route. Since facilities from neighboring states that are within the desired drive time distance (30 minute) can serve Mississippians, facilities from all neighboring states were taken into account for this analysis (Figure 2). This drive time distance area was also used to calculate the \% female outside the desired distance from the mammography facility per public health district in Mississippi (Table 2). The delineated areas 
were superimposed on Census geography (Block Group) to proportionately apportion the demographic data from Census geography to drive time distance area geography. Demographic attributes were obtained from the 2010 U.S. Census data.

\section{MCR Breast cancer data}

Breast cancer incidence and mortality data were obtained from the Mississippi Cancer Registry (http://mcr.umc.edu/) over the years 2005 through 2009 to provide a more reliable "snapshot" of recent cancer statistics in a state dominated by low population density areas. Mississippi has a fairly stable population, as evidenced by U.S. Census data showing that the $0.3 \%$ change in population in Mississippi from 2010 to 2011 was below the national average of $0.9 \%$, and population changes for individual Mississippi counties ranged from $-3.0 \%$ to $3.2 \%$. Breast cancer data were derived from only the female cohort because mammography is not a recommended screening modality for males. Mississippi's Behavioral Risk Factor Surveillance System (BRFSS) Public Health District survey report (http://msdh.ms.gov/brfss/index.htm) was the source of data on the use of mammography in women aged 40 and above were obtained from the District Reports for the years 2005, 2006 and 2008 (this question is not annually included in the BRFSS).

\section{Data Analysis}

Histograms were constructed for the cancer outcome, mammography usage and socio-economic variables to examine the normality of the distributions. Correlation analysis was performed between cancer outcome variables and mammography usage or socio-economic variables to assess the degree of association. The Pearson correlation coefficient was evaluated when both variables were normally distributed. If one variable or both variables had skewed distribution, the Spearman rank correlation coefficient was utilized. Comparison of cancer outcome variables between Black and White women residents was performed using the two-sample T test. All $\mathrm{p}$ values were two-sided and $\mathrm{p}$ values less than 0.05 were considered significant. Statistical analysis was performed using the software SAS (version 9.3, SAS Institute Inc.).

\section{Results}

The GIS mapping of FDA certified mammography facilities in Mississippi is shown in Figure 1. The densest clustering of mammography facilities was located along major Interstate highways. For example, thirteen mammography facilities were on the I-10 corridor that passes through Hancock, Harrison and Jackson Counties along the Gulf Coast, whereas there was only one mammography facility not adjacent to an Interstate highway in the three counties (Pearl River, Stone and George Counties) immediately to the north. Interstate-55 and Interstate-20 intersect in Jackson, Mississippi, and there were sixteen mammography facilities in the tri-county region (Hinds, Madison and Rankin Counties) which defines the greater Jackson Metropolitan Area. In addition to these sixteen facilities, there were seven on I-55 North, four along I-55 South, two on I-20 West and five on I-20 East. Five additional mammography facilities were found along the I59 corridor through Jones, Forrest, Lamar and Pearl River Counties. Thus, of the ninety FDAcertified mammography facilities in Mississippi, 52 (57.8\%) were located along the Interstate highway system. 


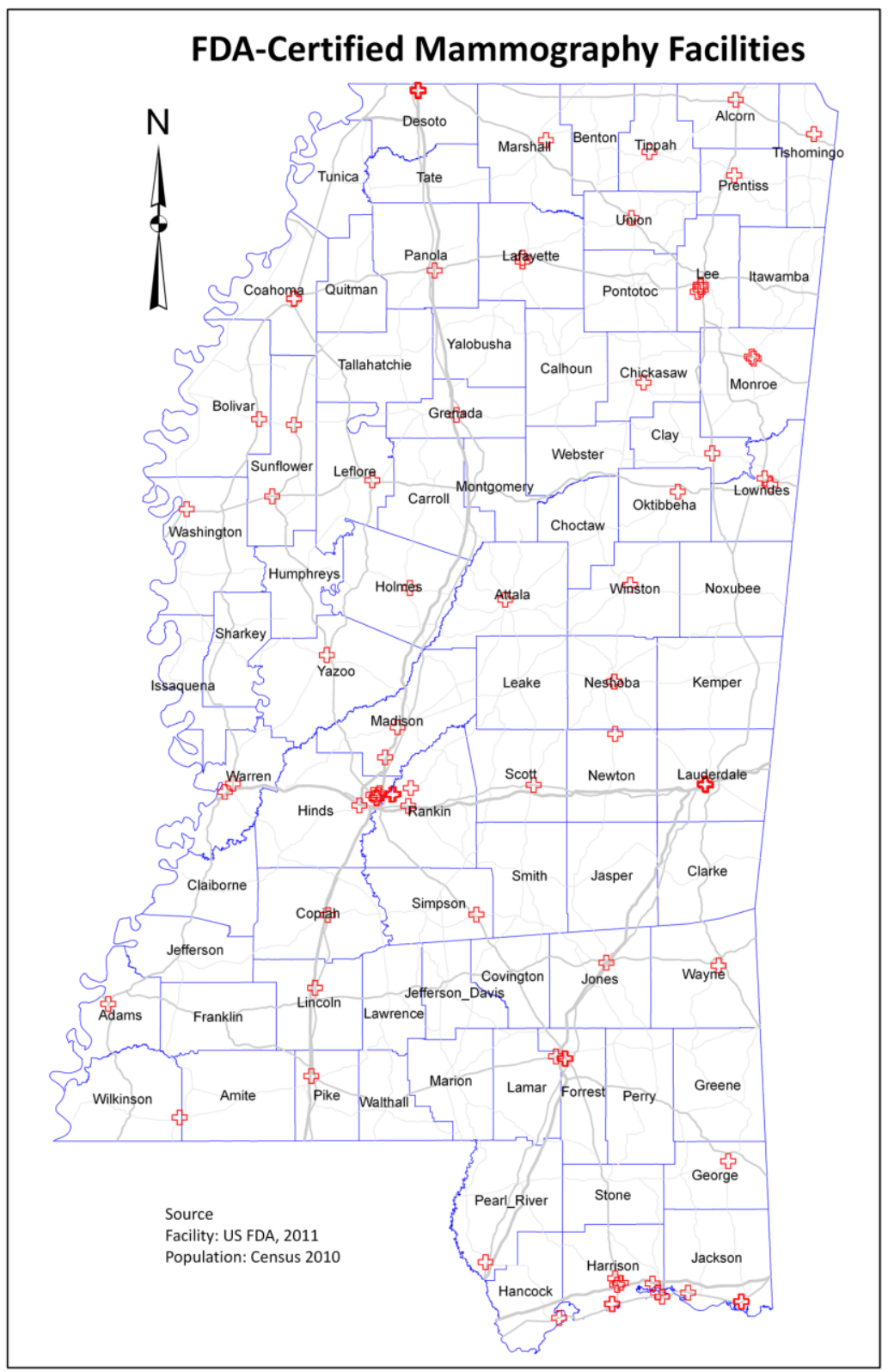

Figure 1. Map of FDA-certified mammography facilities in Mississippi. The U.S. Food and Drug Administration Mammography Facilities database was searched to identify the geographic address of all 90 mammography facilities in Mississippi. These are shown as red crosses on the map, which contains references to the 82 counties of Mississippi and the Interstate highway system. (http://www.accessdata.fda.gov/scripts/cdrh/cfdocs/cfmqsa/mqsa.cfm)

We then sought to estimate how many Mississippi women had convenient access to these facilities, assuming that all women had equal access to automobile transportation. Using the ArcGIS 10.1 software package (Environmental Systems Research Institute, Inc., Redlands, California), we calculated the drive time area in which a driver could travel to a mammography facility within thirty minutes for each facility. These 30-minute drive time areas for Mississippi and its neighboring states are shown in green and purple in Figure 2. Because women who live 
near the state border might choose to travel to mammography facilities outside of Mississippi, we also calculated these 30-minute driving buffer areas for mammography facilities in the neighboring states Louisiana, Arkansas, Tennessee and Alabama which are shown in purple. By integrating the land areas covered within these buffer areas, one can see that $54 \%$ of Mississippi was within a thirty minute drive to a mammography facility. In comparison, $58 \%$ of Louisiana, $43 \%$ of Arkansas, $76 \%$ of Tennessee and $71 \%$ of Alabama were situated within a thirty minutes' drive time to a mammography facility.

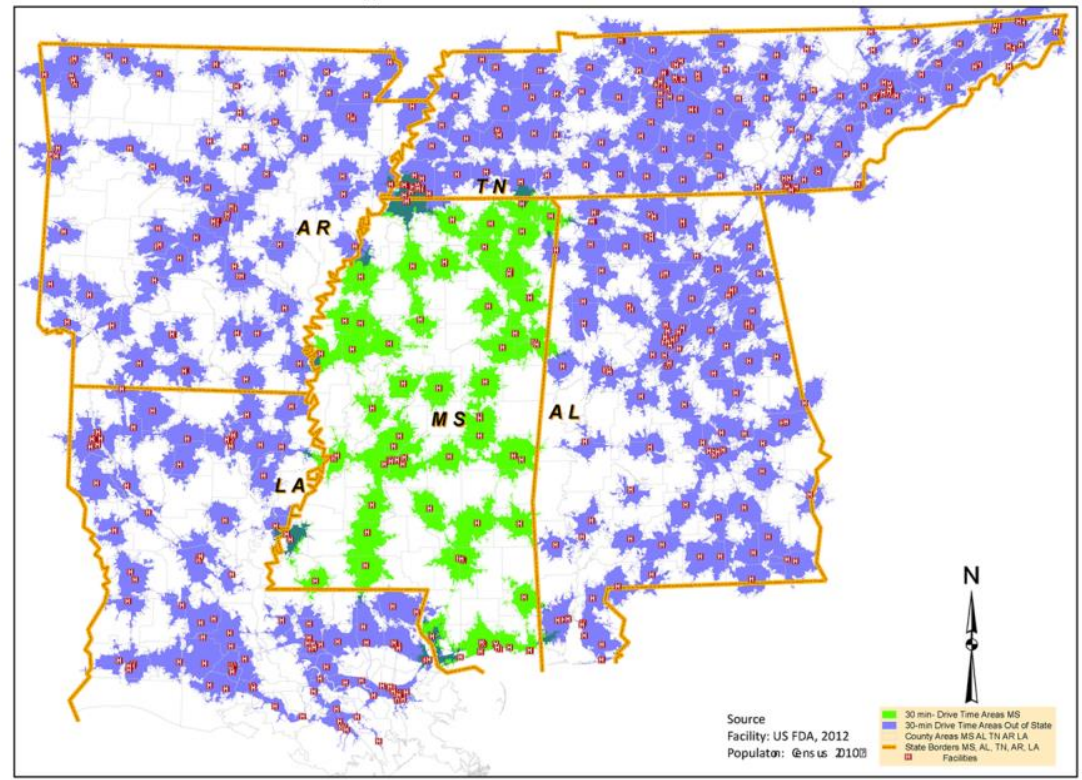

Figure 2. Geographic availability of mammography facilities within a thirty-minute driving radius. This map displays the area that can be reached within a thirty-minute automobile drive from each mammography facility. The green buffer zone indicates areas surrounding Mississippi-based facilities; purple buffers indicate areas surrounding facilities based in the surrounding states of Louisiana, Arkansas, Alabama and Tennessee.

Populations are not uniformly distributed, therefore the above percentages of land area within a thirty minute drive were not equivalent to the percentage of women living within those buffer areas. To determine the percentage of women who live within a thirty-minute drive to a mammography facility, we used 2011 estimated population data based on the 2010 U.S. Census data. Using these data, one can estimate that $84.10 \%$ of Mississippi females of age 40 and above lived within a thirty minute drive to a mammography facility. In comparison, $94.36 \%$ of the females of age 40 and above in Louisiana, 83.21\% of those in Arkansas, $94.50 \%$ of those in Tennessee and $93.04 \%$ of the females in Alabama resided within a thirty minutes' drive time to a mammography facility. Thus, based on both the percentage of land area and the percentage of the female population within a thirty-minute driving area, mammography facilities in Arkansas were slightly less available than they were in Mississippi, and within this five-state territory, mammography facilities were most available in Tennessee. These data are summarized in Table 1. 
Table 1. Geographic distribution of mammography facilities in Mississippi and surrounding states.

\begin{tabular}{|l|l|l|l|l|l|}
\hline Region & Alabama & Arkansas & Louisiana & Mississippi & Tennessee \\
\hline $\begin{array}{l}\text { Number of } \\
\text { FDA-certified } \\
\text { mammography } \\
\text { facilities }\end{array}$ & 130 & 83 & 150 & 90 & 192 \\
\hline $\begin{array}{l}\text { Percentage of } \\
\text { state territory } \\
\text { within 30 } \\
\text { minute drive to } \\
\text { mammography } \\
\text { facility }\end{array}$ & $71 \%$ & $43 \%$ & $58 \%$ & $54 \%$ & $76 \%$ \\
\hline $\begin{array}{l}\text { Percentage of } \\
\text { female residents } \\
\text { within 30 } \\
\text { minute drive to } \\
\text { mammography } \\
\text { facility }\end{array}$ & $93.04 \%$ & $83.21 \%$ & $94.36 \%$ & $84.10 \%$ & $94.50 \%$ \\
\hline
\end{tabular}

Note: The data depicted in Figure 2 are tabulated in Table 1, along with the calculated territorial area and percentage of residents within a thirty-minute driving distance to a mammography facility.

Using such GIS maps, one can assess whether breast cancer outcomes were correlated to the geographic distribution of mammography facilities throughout Mississippi. Considering that Mississippi is a sparsely-populated, predominantly rural state with low population densities, there may be a problem of low statistical power if one uses too small of a geocoded area as the basis for comparison. Thus, the first analysis was conducted at the level of Mississippi's nine Public Health Districts (PHDs). Table 2 contains data derived from various sources which described certain aspects of the Public Health Districts. The data of most interest are the percentages of females (age 40 and above) who reside outside of a thirty-minute drive to a mammography facility. Using public data from the Mississippi Cancer Registry, we examined the age-adjusted breast cancer incidence rates and the age-adjusted breast cancer mortality rates over the years from 2005 to 2009 for each of the state's PHDs. We were particularly interested in knowing whether the availability of mammography resources had a bearing on the breast cancer mortality-to-incidence ratio of the entire female population within these districts. We used this ratio to estimate the likelihood of surviving a diagnosis of breast cancer. The percentage of breast cancers initially diagnosed at an advanced stage (either regional or distant disease) was also considered as a potentially relevant outcome of limited availability of mammography resources. We applied Pearson correlation analysis to the data in Table 2 in pairwise fashion, but we were unable to detect any statistically meaningful correlations between any of these variables and 
breast cancer mortality rates or mortality-to-incidence ratios when applied to the entire female population. However, the analysis revealed a significant negative correlation between the percentage of women who reported having mammography and clinical breast exams and the percentage of women who initially presented with advanced disease at the time of their initial diagnosis. The Pearson sample correlation coefficient is -0.671 with a p value of 0.047 (95\% CI 0.917 to 0.030$)$.

Both the BRFSS data concerning mammography usage and the Mississippi Cancer Registry data concerning stage of disease at initial diagnosis are available as Black and White subsets, and we therefore re-examined these data accordingly and plotted them in Figure 3 (upper panel). It was immediately apparent that the data describing the Black population (blue dots) was distinctly different from the data describing the White population (red crosses) for all nine Public Health Districts (Table 2). This was confirmed by applying the two-sample t test to PHD-level data, which showed that four characteristics were significantly different between the Black and White female subpopulations: 1) the percentage of advanced-stage breast cancers detected at initial diagnosis (40.8\% in Black women vs. $31.5 \%$ in White women; $p<0.0001) ; 2$ ) the percentage of females age 40 and older who had mammography and clinical breast exams $(73.13 \%$ in Black women vs. $82.57 \%$ in White women; $\mathrm{p}=0.0001)$; 3 ) the age-adjusted breast cancer mortality rate (33.38 per 100,000 in Black women vs. 20.16 per 100,000 in White women; $\mathrm{p}=0.0003$ ); and 4) the breast cancer mortality-to-incidence ratio (0.2442 in Black women vs. 0.1509 in White women; $\mathrm{p}=0.0005)$. Unfortunately, in all four of these characteristics, Black females fared worse than White females in Mississippi, confirming that the extent of population-based breast cancer is pervasive throughout all nine PHDs in the state. Only one characteristic was not statistically different, and that is the age-adjusted breast cancer incidence rate $(p=0.735)$.

Table 2. Data characteristics of female breast cancer and breast cancer screening resources in Mississippi's Public Health Districts.

\begin{tabular}{|l|l|l|l|l|l|l|l|l|}
\hline Region & $\begin{array}{l}\text { Mammogr } \\
\text { aphy } \\
\text { facilities }\end{array}$ & $\begin{array}{l}\text { Women per } \\
\text { mammograph } \\
\text { y facility }\end{array}$ & $\begin{array}{l}\text { Age- } \\
\text { Adjusted } \\
\text { Breast } \\
\text { Cancer } \\
\text { Incidence } \\
\text { rate (all } \\
\text { female per } \\
100,000 ; \\
2005-2009\end{array}$ & $\begin{array}{l}\text { Age- } \\
\text { Adjusted } \\
\text { Breast } \\
\text { Cancer } \\
\text { Mortality } \\
\text { rate (all } \\
\text { female per } \\
100,000 ; \\
2005-\end{array}$ & $\begin{array}{l}\text { Breast } \\
\text { Cancer } \\
\text { Mortality } \\
\text { to- } \\
\text { Incidenc } \\
\text { e Ratio }\end{array}$ & $\begin{array}{l}\text { \% High- } \\
\text { stage } \\
\text { Regional } \\
\text { + Distant) } \\
\text { at } \\
\text { Diagnosis }\end{array}$ & $\begin{array}{l}\text { \% Females } \\
\text { (age 40+) who } \\
\text { had } \\
\text { mammography } \\
\text { \& clinical } \\
\text { breast exam }\end{array}$ & $\begin{array}{l}\text { Females } \\
\text { (age 40+) } \\
\text { beyond 30 } \\
\text { minute drive to } \\
\text { mammography } \\
\text { facility }\end{array}$ \\
\hline Mississippi & 90 & 16900 & 134.96 & 24.27 & 0.1798 & 0.342 & $79.43 \%$ & $15.88 \%$ \\
\hline $\begin{array}{l}\text { Northwest } \\
\text { Public Health } \\
\text { District 1 }\end{array}$ & 8 & 20384 & 130.70 & 24.73 & 0.1892 & 0.373 & $74.43 \%$ & $15.44 \%$ \\
\hline $\begin{array}{l}\text { Northeast } \\
\text { Public Health } \\
\text { District 2 }\end{array}$ & 13 & 13927 & 130.97 & 24.83 & 0.1896 & 0.341 & $78.20 \%$ & $11.65 \%$ \\
\hline
\end{tabular}




\begin{tabular}{|l|l|l|l|l|l|l|l|l|}
\hline $\begin{array}{l}\text { Delta/Hills } \\
\text { Public Health } \\
\text { District 3 }\end{array}$ & 7 & 16817 & 123.51 & 31.30 & 0.2534 & 0.368 & $74.87 \%$ & $14.83 \%$ \\
\hline $\begin{array}{l}\text { Tombigbee } \\
\text { Public Health } \\
\text { District 4 }\end{array}$ & 8 & 15869 & 127.44 & 21.10 & 0.1656 & 0.338 & $79.27 \%$ & $21.17 \%$ \\
\hline $\begin{array}{l}\text { West Central } \\
\text { Public Health } \\
\text { District 5 }\end{array}$ & 21 & 15696 & 155.31 & 24.82 & 0.1598 & 0.332 & $83.53 \%$ & $11.68 \%$ \\
\hline $\begin{array}{l}\text { East Central } \\
\text { Public Health } \\
\text { District 6 }\end{array}$ & 8 & 15754 & 125.48 & 19.53 & 0.1556 & 0.362 & $78.63 \%$ & $21.34 \%$ \\
\hline $\begin{array}{l}\text { Southwest } \\
\text { Public Health } \\
\text { District 7 }\end{array}$ & 5 & 18180 & 125.60 & 32.42 & 0.2581 & 0.367 & $80.93 \%$ & $28.32 \%$ \\
\hline $\begin{array}{l}\text { Southeast } \\
\text { Public Health } \\
\text { District 8 }\end{array}$ & 5 & 31196 & 130.66 & 22.04 & 0.1687 & 0.335 & $81.23 \%$ & $26.12 \%$ \\
\hline $\begin{array}{l}\text { Coastal Plains } \\
\text { Public Health } \\
\text { District 9 }\end{array}$ & 15 & 15308 & 135.15 & 21.73 & 0.1608 & 0.310 & $81.03 \%$ & $8.40 \%$ \\
\hline
\end{tabular}

Note: The characteristics listed in this table include the number of mammography facilities, the number of women per mammography facility, the age-adjusted breast cancer incidence and mortality rates, the mortality-to-incidence ratios, the percentage breast cancers initially diagnosed at advanced stage (regional + distant disease), the percentage of women (age 40 and older) who reported ever receiving a mammogram and clinical breast exam, and the percentage of women residing beyond a 30 minute driving distance from a mammography facilities in each of Mississippi's Public Health Districts.

Given the magnitude of these disparities, we performed correlation analyses on Black and White subsets to determine whether the use of mammography in either Black or White women was correlated to advanced stage at initial diagnosis for either group. The Pearson correlation coefficient was -0.861 ( $\mathrm{p}=0.001,95 \% \mathrm{CI}-0.967$ to -0.416$)$ for Black women, but did not reach statistical significance for White women, which reflects the more homogeneous use patterns amongst White women throughout the state. Interestingly, when the Black and White subsets were recombined, the common Pearson correlation coefficient was -0.920 ( $p<0.0001,95 \%$ CI 0.968 to -0.783 ), indicating a strong correlation. Only when the Black and White subsets were recombined was it possible to observe a significant Pearson correlation between the mortality-toincidence ratio and the percentage of women with advanced stage breast cancer at initial diagnosis (Pearson coefficient $=0.771, \mathrm{p}=0.0001,95 \% \mathrm{CI} 0.457$ to 0.906 ). While no si gnificant correlation existed between mortality-to-incidence ratio and mammography use in either the Black or the White subsets, a significant correlation (Pearson correlation coefficient $=-0.728, \mathrm{p}$ $<0.0001,95 \%$ CI -0.887 to -0.376 ) was observed upon recombination of these disparate subsets (Fig 3, lower panel). 

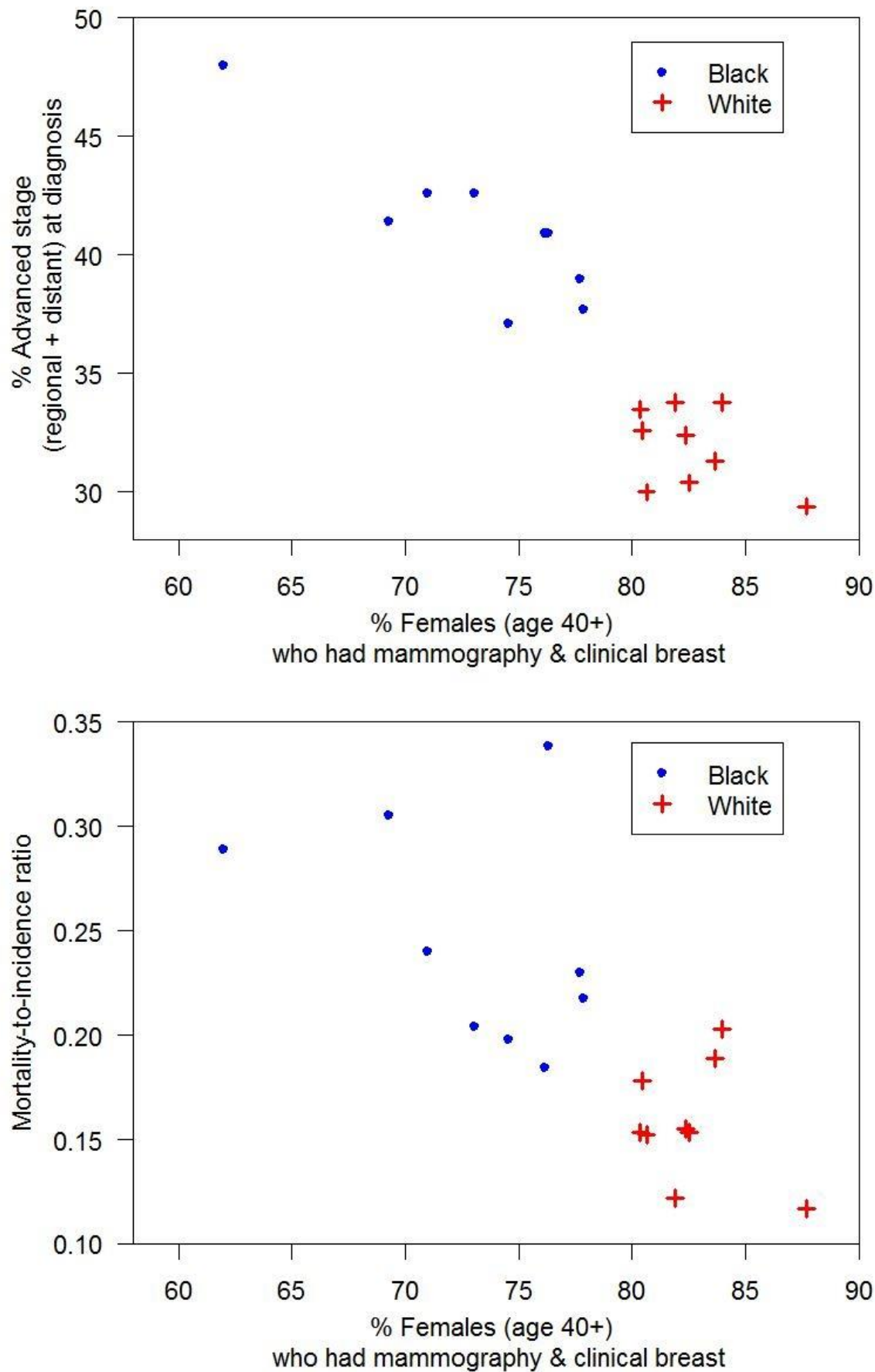

Figure 3. Public Health District patterns of mammography use are inversely correlated with adverse breast cancer outcomes. Mississippi BRFSS Public Health District survey report data (http://msdh.ms.gov/brfss/index.htm) from Black female (blue dots) and White female (red crosses) respondents were obtained from the District Reports for the years 2005, 2006 and 2008, then averaged and plotted along the abscissa. UPPER PANEL: The percentage of women initially diagnosed with advanced stage breast cancer (defined as the sum of the percentages of regional and distant disease initial diagnoses over the years 2005 through 2009) calculated from Mississippi Cancer Registry data for each of the nine Public Health Districts 
(http://mcr.umc.edu/documents/FemaleBreastPHDDataCombinedYears20052009new.pdf), then plotted against the ordinate. These Black and White subsets were subjected to a common Pearson analysis to obtain a correlation coefficient of -0.920 ( $p<0.0001)$. LOWER PANEL: Ageadjusted breast cancer incidence and mortality rates were obtained from the Mississippi Cancer Registry (http://www.cancer-rates.info/ms/index.php) for Black and White women over the years 2005 through 2009 for each of the nine Public Health Districts, and the ratio of mortality-toincidence was calculated and plotted along the ordinate. The Pearson correlation coefficient between these two variables was $-0.728(\mathrm{p}<0.0001)$.

The observation shown in Figure 3 is consistent with other published evidence that because ageappropriate mammography is capable of detecting early-stage breast cancer, broad usage of screening mammography can reduce the proportion of advanced-stage breast cancers at initial diagnosis [33]. The problem appeared to be most severe in the Northwest Public Health District 1 , where only $62 \%$ of Black women age 40 and older reported ever having received mammography and clinical breast exam, and where $48 \%$ of the initial breast cancer diagnoses reveal advanced stage disease in Black women. It is interesting to note that at the PHD level, there was no statistically significant negative correlation between the percentage of women reporting mammography usage and the percentage of women who must drive more than thirty minutes to reach a mammography facility (Pearson correlation coefficient $=0.119, \mathrm{p}=0.769$ ). Nor was there a statistically meaningful negative correlation at the PHD level between the percentage of advanced-stage disease at diagnosis and the percentage of women who must drive more than thirty minutes to reach a mammography facility (Pearson correlation coefficient $=$ $0.413, \mathrm{p}=0.281$ ). However, one must note that we were unable to distinguish between the geographic availability of mammography resources for Black versus White women within any given geographic region, so we were unable to perform subset correlation analyses for this variable. Thus, if there was any effect of the availability of mammography facilities on breast cancer outcomes, then our analysis was inadequate to detect this effect.

It is reasonable to assume that by examining data at the Public Health District level, important demographic details may be hidden due to the homogenization of small geographic tracts with distinctive characteristics. Using public data from the Mississippi Cancer Registry, we further examined age-adjusted breast cancer incidence rates and age-adjusted breast cancer mortality rates over the years from 2005 to 2009 for all of the state's counties. Even with this long time interval, data from Issaquena County must be censored because that county's population is less than 1700; therefore Issaquena County data will be excluded from further consideration. We initially applied Spearman rank correlation analysis to determine whether, at the county level, either breast cancer incidence, breast cancer mortality, breast cancer mortality-to-incidence ratios or the percentage of advanced-stage breast cancers detected at initial diagnosis were associated to the percentage of females age 40 and above residing outside of a thirty-minute drive to a mammography facility. Because this is the only variable with skewed distribution, the Spearman rank correlation coefficient is a suitable criterion for association assessment. The Spearman rank correlation coefficient for the association between the percentage of advanced-stage breast cancers detected at initial diagnosis and the percentage of females age 40 and above residing outside of a thirty-minute drive to a mammography facility was 0.208 , but this association did not reach statistical significance $(\mathrm{p}=0.063)$. Thus, neither county-level data nor PHD-level data can detect a statistically-significant association between the availability of mammography resources and stage of disease at initial diagnosis. Further analysis of county level data reveals no 
statistically meaningful correlation between the geographic availability of mammography facilities (as measured by the percentage of females residing outside of a thirty-minute drive to a mammography facility) and either breast cancer mortality rates $(\mathrm{p}=0.681)$ or the mortality-toincidence ratios $(\mathrm{p}=0.984)$. Unfortunately, at the county level we lacked sufficient data (such as the BRFSS data) to measure the accessibility of mammography resources.

When we looked for correlations between other potentially relevant parameters (\% of population below poverty level, median household income, \% high school graduates aged 25 and above, \% Black, and \% White), two statistically-meaningful correlations were observed. There was a moderate correlation between breast cancer mortality-to-incidence ratios and the percentage of the population living below the poverty level (Figure 4, lower panel). The Pearson correlation coefficient for these two parameters was 0.504 (95\% CI 0.318 to 0.649 ), with a $\mathrm{p}$ value of $<0.0001$. There was also a moderate correlation between breast cancer mortality rates and the percentage of the population who are Black (Figure 4, upper panel). The Pearson correlation coefficient for these two parameters was 0.422 (95\% CI 0.222 to 0.585 ), with a $\mathrm{p}$ value of $<0.0001$. It is very important to note that, in Mississippi, the two parameters were strongly correlated. The Pearson correlation coefficient between the percentage of Black residents in a county and the percentage of the population in that county who live below the poverty level was 0.802 (95\% CI 0.706 to 0.867 ), with a $\mathrm{p}$ value of $=0.0001$.

Based on the breast cancer disparities between Black and White women in Mississippi observed in the preceding Public Health District data, cancer outcome comparison between Black and White women using the county-level data may prove insightful. Due to the rural nature of Mississippi, data from several counties could not be considered in this subset analysis because the Black or White population in those counties was less than 1700. Therefore Benton, Choctaw, Franklin, George, Greene, Hancock, Issaquena, Itawamba, Perry, Stone and Tishomingo County data were excluded from the Black female subset, and Claiborne, Jefferson, Humphreys, Issaquena, Noxubee, Quitman, Sharkey, Tunica and Wilkinson County data were excluded from the White female subset. The two-sample t test was applied to county-level data, which confirmed that two characteristics were significantly different between the Black and White female subpopulations: 1) the age-adjusted breast cancer mortality rate ( $\mathrm{p}<0.0001)$ and 2$)$ the breast cancer mortality-to-incidence ratio $(\mathrm{p}<0.0001)$. Again, Black females fared worse than White females in Mississippi, confirming that the existence of significant population-based breast cancer mortality disparities in Mississippi. As observed at the Public Health District level, the age-adjusted breast cancer incidence rate was not statistically different between Black females and White females in Mississippi $(\mathrm{p}=0.735)$. 

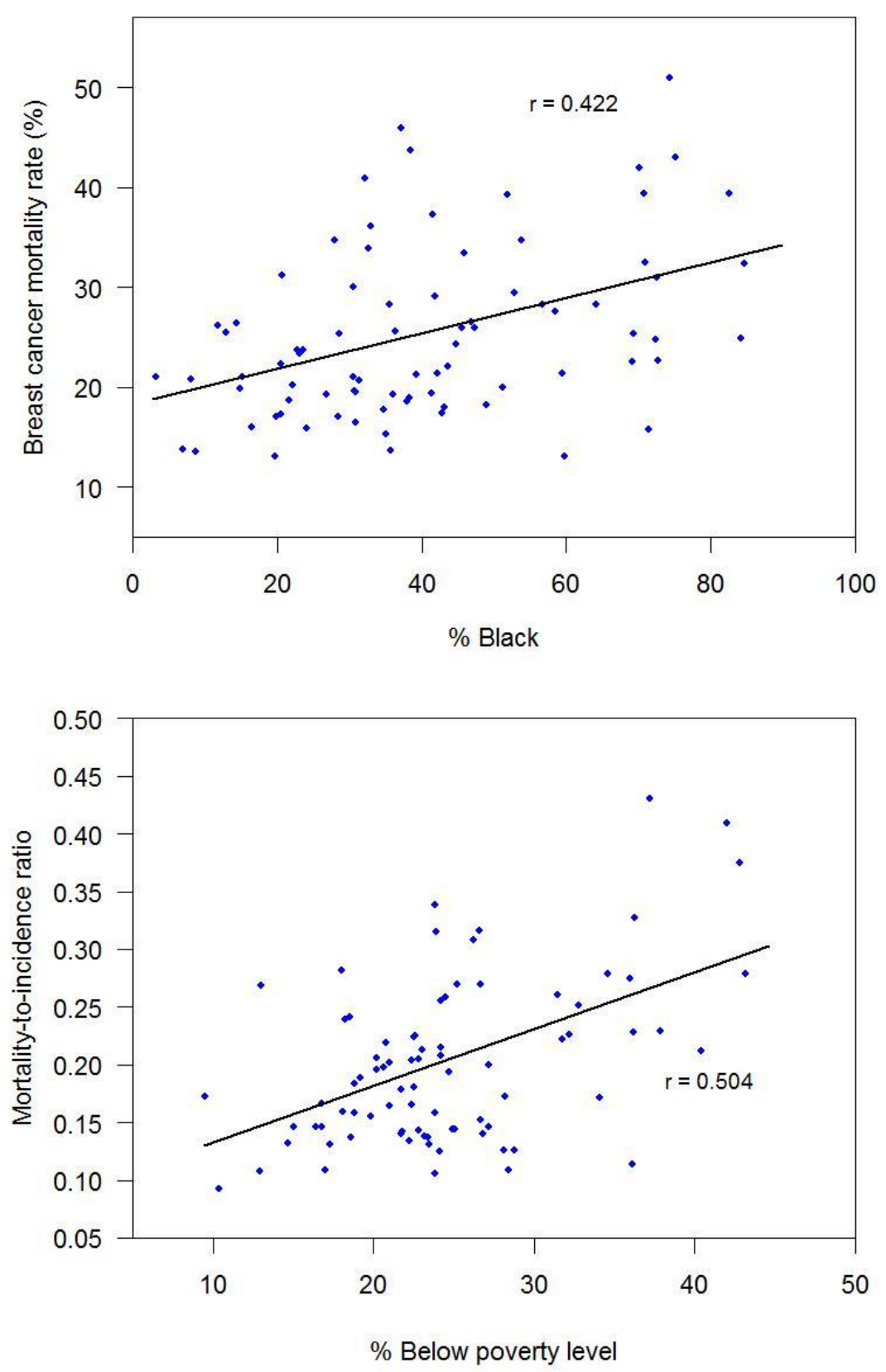

Figure 4. County-associated parameters correlated with breast cancer mortality outcomes. Breast cancer incidence and survival data were obtained from the Mississippi Cancer Registry; demographic data were obtained from the U.S. Census (http://quickfacts.census.gov/qfd/states/28000.html); all Mississippi counties are represented, with the exception of Issaquena County. UPPER PANEL: Age-adjusted breast cancer mortality rates correlated with the percentage of the population who are Black; the Pearson sample correlation between these two variables was 0.422 ( $\mathrm{p}<0.0001$ ). LOWER PANEL: The ratios of BC mortality-to-incidence were correlated with the percentages of population living below poverty level; the Pearson sample correlation between these two variables was 0.504 ( $p$ $<0.0001)$. 
County-level subset correlation analyses confirmed several of the observations at the PHD level: there was no statistically-significant correlation between the availability of mammography resources (as measured by the \% of women residing within a 30 minute drive to a mammography facility) and either the breast cancer incidence rate, the breast cancer mortality rate, or the mortality-to-incidence ratios for either the Black female or the White female subsets. Perhaps more importantly, the correlation between the percentage of population living below poverty level and the mortality-to-incidence ratio was observed for Black females (Pearson correlation coefficient $=0.346, \mathrm{p}=0.003,95 \%$ CI 0.120 to 0.534 ), but surprisingly, not for White female subsets $(p=0.274)$. One must guard against over-interpretation of the latter observation because the "percentage of population living below poverty level" data were unadjusted for race and were determined at the county level. Due to the low populations at risk, some of the counties with the highest percentage of residents living below the poverty level in Mississippi (Claiborne, Jefferson, Humphreys, Noxubee, Quitman, and Sharkey counties) were excluded from the White female subset, which may have introduced bias against detecting the effect of poverty in this subset. Conversely, some of the counties with the lowest percentage of residents living below the poverty level (George, Stone and Itawamba counties) were excluded from the Black female subset, which may have introduced bias towards detecting the effect of poverty in this subset. This reflected of the strong correlation between race and poverty in Mississippi; a Pearson correlation coefficient of $0.802(\mathrm{p}<0.0001)$ exists between the percentage of population who are Black and the percentage of population living below the poverty level.

\section{Discussion}

One cannot properly assess the burden of breast cancer in Mississippi without recognizing the problem of population-based disparities. This study initially sought to assess whether geographic disparities existed based on the statewide distribution of mammography facilities, but data analysis quickly revealed that poverty and race were the dominant characteristics affecting geographic disparities in breast cancer outcomes in Mississippi. At the county level, the percentage of population below poverty level and the percentage of population who are Black are strongly correlated. Thus, it is apparent that breast cancer places a disparate burden on poor African-American communities in Mississippi. This study was not designed to include direct measures of the impact of aggressive "triple-negative" breast cancer subtypes, so one can only assume that it contributes to the disproportionate mortality rates observed in Black Mississippians, as discussed in the Introduction section. Recent analysis of national breast cancer data confirm that poverty and race remain as dominant risk factors in breast cancer mortality and that screening rates are lower in poorer women than in wealthier women [33]. The data shown in Figure 3 indicate that the proportion of advanced-stage breast cancers at initial diagnosis in African-American women could be significantly reduced through a concerted campaign to increase the rate of participation in mammographic breast screening in African-American women in Mississippi. A decrease in the proportion of breast cancers diagnosed at an advanced stage may affect not only mortality rates (the probability of long-term survival is strongly negatively correlated with stage), but also additional parameters. These include among others the cost and morbidity associated with treatment (advanced stage breast cancers that recur require additional chemotherapy, imaging and often salvage procedures such as spine stabilization, brain irradiation etc.). It is not entirely clear why there was no apparent correlation between the availability of mammography facilities and the use of mammography. Further studies designed for the county level of geographic resolution, or in selected communities, may identify the community-specific 
barriers to mammographic use, and hopefully these barriers can be overcome through community-targeted educational outreach campaigns.

It has been estimated that 84 women between the ages of 40 and 84 need to be screened annually in order to save one life from breast cancer [34]. Care must be taken to note that screening alone is inadequate in Mississippi if the true objective is to increase breast cancer survivorship; women who receive positive screening results must also receive appropriate follow-up care. A proposal to increase breast cancer screening participation should address whether such an effort in Mississippi would result in problems associated with overdiagnosis of breast cancer. By definition, overdiagnosis occurs through the detection of cancers that would not otherwise cause symptoms or death to occur within the lifetime of an individual [35]. Overdiagnosis, by itself, can create needless emotional stress and anxiety considered harmful to a person's wellbeing, but the major harm associated with the overdiagnosis of breast cancer arises from overtreatment that often accompanies overdiagnosis. Estimates for the overdiagnosis of breast cancer vary tremendously. A study of Norwegian women estimated that approximately $15 \%$ to $25 \%$ of breast cancer cases were overdiagnosed [36], and estimates as high as $42 \%$ overdiagnosed breast cancers were obtained from an Australian cohort [37]. Studies reporting overdiagnosis predominantly involve European populations or populations of European ancestry, and are focused on ductal carcinoma in situ (DCIS), a non-invasive form of breast cancer which ranges from low-grade to high-grade. Although DCIS is considered non-invasive, clinicians are currently unable to predict which specific cases of DCIS are highly likely to progress, and which cases are likely to remain indolent and can be safely left untreated. The increasing frequency of routine mammography screening is considered to be the cause of the increasing diagnosis of DCIS, which had an incidence of less than 2 per 100,000 women in the early 1970s and thirty years later, had an incidence of approximately 32 per 100,000 women [38]. Approximately 1 in 1300 mammograms will result in a diagnosis of DCIS [39], which accounts for approximately $20 \%$ to $25 \%$ of breast cancer diagnoses in the U.S.A. today [38]. However, there are no indications that overdiagnosis and overtreatment of breast cancer is currently a significant problem in Mississippi, where the percentage of DCIS at initial diagnosis is lower than the national average [33] and where the underuse of mammography appears to be linked to increased probability of mortality after diagnosis.

\section{Conclusion}

As previously discussed, one cannot properly assess the burden of breast cancer in Mississippi without recognizing the problem of population-based disparities. This study initially sought to determine whether the geographic availability of mammography resources influenced breast cancer outcomes, but data analysis quickly revealed that poverty and race were the dominant characteristics affecting geographic disparities in breast cancer outcomes in Mississippi. The data presented in this manuscript supports two general observations pertaining to Mississippi's cancer control efforts. First, intensified mammography campaigns to reduce the percentage of advanced-stage breast cancers initially diagnosed in Black women are justified and warranted. Second, efforts are needed to ensure that once breast cancers are diagnosed, effective medical treatment will occur, especially for all women living in poverty. 


\section{Limitations}

Before discussing the above results, the following limitations of the study design should be noted. These studies were based on publicly available data, and as such, all health and economic data were analyzed in aggregate form. Data were not obtained at the individual level, so the interpretations and implications of the evidence are limited to broadly defined localities and communities. Out of respect for individual medical privacy, public cancer registry data are censored for statistically sparse counties, so some women with breast cancer were excluded from this study based on their place of residence (e.g., Issaquena County). Finally, to compensate for such problems associated with the low population density in many parts of Mississippi, a fiveyear data collection window was used based on the assumption that the recent trends in breast cancer outcomes have remained reasonably stable.

\section{Acknowledgements}

The authors would like to acknowledge Dr. Robin Rockhold and the Base Pair Program for sponsoring science mentorship in central Mississippi for over twenty years, and for providing numerous high school students with opportunities to design and conduct scientific research in a professional environment. The authors also acknowledge Dr. Donna Sullivan, Ms. Gail Howell and Mr. Jeffrey Stokes for their essential roles in the Base Pair Program, and they gratefully acknowledge the financial support of the Base Pair Program (funded by the Howard Hughes Medical Institute). The authors gratefully acknowledge the advice and assistance of Ms. Deirdre Rogers and data provided by the Mississippi Cancer Registry. The helpful comments of Dr. Lucio Miele and Dr. Marinelle Payton are greatly appreciated.

\section{Conflicts of Interest}

RJD is a member of the Advisory Board of the Mississippi Cancer Registry and the Medical/Research Advisor to the Mississippi Partnership for Comprehensive Cancer Control Executive Board. Otherwise, the authors have no conflicts of interests to report.

\section{References}

1. Miller JW, King JB, Joseph DA, Richardson LC. 2012. Breast cancer screening among adult women-Behavioral Risk Factor Surveillance System, United States, 2010. MMWR Morb Mortal Wkly Rep. 61(Suppl), 46-50. PubMed

2. Berry DA, Cronin KA, Plevritis SK, Fryback DG, Clarke L, et al. 2005. Effect of screening and adjuvant therapy on mortality from breast cancer. $N$ Engl J Med. 353(17), 1784-92. PubMed http://dx.doi.org/10.1056/NEJMoa050518

3. van Ravesteyn NT, Schechter CB, Near AM, Heijnsdijk EA, Stoto MA, et al. 2011. Race-specific impact of natural history, mammography screening, and adjuvant treatment on breast cancer mortality rates in the United States. Cancer Epidemiol Biomarkers Prev. 20(1), 112-22. PubMed http://dx.doi.org/10.1158/10559965.EPI-10-0944

4. Ryan CLS. J. Educational Attainment in the United States: 2009. Population Characteristics. 2012;P20-566. 
5. Aud S, Hussar W, Johnson F, Kena G, Roth E, et al. The Condition of Education 2012. (NCES 2012-045) US Department of Education, National Center for Education Statistics Washington, DC. 2012.

6. Macartney S. Child Poverty in the United States 2009 and 2010: Selected Race Groups and Hispanic Origin. American Community Survey Briefs. 2011;November 2011(ACSBR/1005):1-16.

7. Macartney SM, L. Poverty and Shared Households by State: 2011. American Community Survey Briefs. 2012;ACSBR/11-05.

8. Albano JD, Ward E, Jemal A, Anderson R, Cokkinides VE, et al. 2007. Cancer mortality in the United States by education level and race. $J$ Natl Cancer Inst. 99(18), 1384-94. $\underline{\text { PubMed }}$ http://dx.doi.org/10.1093/jnci/djm127

9. Du XL, Lin CC, Johnson NJ, Altekruse S. 2011. Effects of individual-level socioeconomic factors on racial disparities in cancer treatment and survival: findings from the National Longitudinal Mortality Study, 19792003. Cancer. 117(14), 3242-51. PubMed http://dx.doi.org/10.1002/cncr.25854

10. Sprague BL, Trentham-Dietz A, Gangnon RE, Ramchandani R, Hampton JM, et al. 2011. Socioeconomic status and survival after an invasive breast cancer diagnosis. Cancer. 117(7), 1542-51. PubMed http://dx.doi.org/10.1002/cncr.25589

11. Schootman M, Lian M, Deshpande AD, Baker EA, Pruitt SL, et al. 2010. Temporal trends in area socioeconomic disparities in breast-cancer incidence and mortality, 1988-2005. Breast Cancer Res Treat. 122(2), 533-43. PubMed http://dx.doi.org/10.1007/s10549-009-0729-y

12. Maly RC, Leake B, Mojica CM, Liu Y, Diamant AL, et al. 2011. What influences diagnostic delay in lowincome women with breast cancer? J Womens Health (Larchmt). 20(7), 1017-23. PubMed http://dx.doi.org/10.1089/jwh.2010.2105

13. Adams SA, Smith ER, Hardin J, Prabhu-Das I, Fulton J, et al. 2009. Racial differences in follow-up of abnormal mammography findings among economically disadvantaged women. Cancer. 115(24), 5788-97. PubMed http://dx.doi.org/10.1002/cncr.24633

14. Perou CM, Sorlie T, Eisen MB, van de Rijn M, Jeffrey SS, et al. 2000. Molecular portraits of human breast tumours. Nature. 406(6797), 747-52. PubMed http://dx.doi.org/10.1038/35021093

15. Sørlie T, Perou CM, Tibshirani R, Aas T, Geisler S, et al. 2001. Gene expression patterns of breast carcinomas distinguish tumor subclasses with clinical implications. Proc Natl Acad Sci USA. 98(19), 1086974. PubMed http://dx.doi.org/10.1073/pnas.191367098

16. Haiman CA, Chen GK, Vachon CM, Canzian F, Dunning A, et al. 2011. A common variant at the TERTCLPTM1L locus is associated with estrogen receptor-negative breast cancer. Nat Genet. 43(12), 1210-14. PubMed http://dx.doi.org/10.1038/ng.985

17. Chen X, Li J, Gray WH, Lehmann BD, Bauer JA, et al. 2012. TNBCtype: A Subtyping Tool for TripleNegative Breast Cancer. Cancer Inform. 11, 147-56. PubMed http://dx.doi.org/10.4137/CIN.S9983

18. Lehmann BD, Bauer JA, Chen X, Sanders ME, Chakravarthy AB, et al. 2011. Identification of human triplenegative breast cancer subtypes and preclinical models for selection of targeted therapies. J Clin Invest. 121(7), 2750-67. PubMed http://dx.doi.org/10.1172/JCI45014

19. Amirikia KC, Mills P, Bush J, Newman LA. 2011. Higher population-based incidence rates of triple-negative breast cancer among young African-American women: Implications for breast cancer screening recommendations. Cancer. 117(12), 2747-53. PubMed http://dx.doi.org/10.1002/cncr.25862

20. Parise CA, Bauer KR, Caggiano V. 2010. Variation in breast cancer subtypes with age and race/ethnicity. Crit Rev Oncol Hematol. 76(1), 44-52. http://dx.doi.org/10.1016/j.critrevonc.2009.09.002 
21. Carey LA, Perou CM, Livasy CA, Dressler LG, Cowan D, et al. 2006. Race, breast cancer subtypes, and survival in the Carolina Breast Cancer Study. JAMA. 295(21), 2492-502. PubMed http://dx.doi.org/10.1001/jama.295.21.2492

22. O'Brien KM, Cole SR, Tse CK, Perou CM, Carey LA, et al. 2010. Intrinsic breast tumor subtypes, race, and long-term survival in the Carolina Breast Cancer Study. Clin Cancer Res. 16(24), 6100-10. PubMed http://dx.doi.org/10.1158/1078-0432.CCR-10-1533

23. Morris GJ, Naidu S, Topham AK, Guiles F, Xu Y, et al. 2007. Differences in breast carcinoma characteristics in newly diagnosed African-American and Caucasian patients: a single-institution compilation compared with the National Cancer Institute's Surveillance, Epidemiology, and End Results database. Cancer. 110(4), 876-84. PubMed http://dx.doi.org/10.1002/cncr.22836

24. Stark A, Kleer CG, Martin I, Awuah B, Nsiah-Asare A, et al. 2010. African ancestry and higher prevalence of triple-negative breast cancer: findings from an international study. Cancer. 116(21), 4926-32. PubMed http://dx.doi.org/10.1002/cncr.25276

25. Chu QD, Henderson AE, Ampil F, Li BD. Outcome for patients with triple-negative breast cancer is not dependent on race/ethnicity. Int J Breast Cancer. 2012;2012:764570.

26. Dawood S, Broglio K, Kau SW, Green MC, Giordano SH, et al. 2009. Triple receptor-negative breast cancer: the effect of race on response to primary systemic treatment and survival outcomes. J Clin Oncol. 27(2), 220-26. PubMed http://dx.doi.org/10.1200/JCO.2008.17.9952

27. Wang S, Dorsey TH, Terunuma A, Kittles RA, Ambs S, et al. 2012. Relationship between tumor DNA methylation status and patient characteristics in African-American and European-American women with breast cancer. PLoS ONE. 7(5), e37928. PubMed http://dx.doi.org/10.1371/journal.pone.0037928

28. Nelson HD, Tyne K, Naik A, Bougatsos C, Chan BK, Humphrey L. Screening for breast cancer: an update for the U.S. Preventive Services Task Force. Ann Intern Med. 2009;151(10):727-37, W237-42.

29. 2002. Screening for breast cancer: recommendations and rationale. Ann Intern Med. 137(5 Part 1), 344-46. PubMed

30. Screening for breast cancer: U.S. Preventive Services Task Force recommendation statement. Ann Intern Med. 2009;151(10):716-26, W-236.

31. Yasmeen S, Romano PS, Tancredi DJ, Saito NH, Rainwater J, et al. 2012. Screening mammography beliefs and recommendations: a web-based survey of primary care physicians. BMC Health Serv Res. 12, 32. PubMed http://dx.doi.org/10.1186/1472-6963-12-32

32. Smith RA, Cokkinides V, Brooks D, Saslow D, Brawley OW. 2010. Cancer screening in the United States, 2010: a review of current American Cancer Society guidelines and issues in cancer screening. CA Cancer J Clin. 60(2), 99-119. PubMed http://dx.doi.org/10.3322/caac.20063

33. DeSantis C, Siegel R, Bandi P, Jemal A. 2011. Breast cancer statistics, 2011. CA Cancer J Clin. 61(6), 40818. PubMed http://dx.doi.org/10.3322/caac.20134

34. Hendrick RE, Helvie MA. 2012. Mammography screening: a new estimate of number needed to screen to prevent one breast cancer death. AJR Am J Roentgenol. 198(3), 723-28. $\underline{\text { PubMed }}$ http://dx.doi.org/10.2214/AJR.11.7146

35. Welch HG, Black WC. 2010. Overdiagnosis in cancer. J Natl Cancer Inst. 102(9), 605-13. PubMed http://dx.doi.org/10.1093/jnci/djq099

36. Kalager M, Adami HO, Bretthauer M, Tamimi RM. 2012. Overdiagnosis of invasive breast cancer due to mammography screening: results from the Norwegian screening program. Ann Intern Med. 156(7), 491-99. PubMed http://dx.doi.org/10.7326/0003-4819-156-7-201204030-00005

37. Morrell S, Barratt A, Irwig L, Howard K, Biesheuvel C, et al. 2010. Estimates of overdiagnosis of invasive breast cancer associated with screening mammography. Cancer Causes Control. 21(2), 275-82. PubMed http://dx.doi.org/10.1007/s10552-009-9459-z 
38. Virnig BA, Tuttle TM, Shamliyan T, Kane RL. 2010. Ductal carcinoma in situ of the breast: a systematic review of incidence, treatment, and outcomes. J Natl Cancer Inst. 102(3), 170-78. PubMed http://dx.doi.org/10.1093/jnci/djp482

39. Ernster VL, Ballard-Barbash R, Barlow WE, Zheng Y, Weaver DL, et al. 2002. Detection of ductal carcinoma in situ in women undergoing screening mammography. J Natl Cancer Inst. 94(20), 1546-54. PubMed http://dx.doi.org/10.1093/jnci/94.20.1546 